\title{
RECURSO EXTRAORDINÁRIO NO NCPC
}

\author{
Priscila Martins Merlo
}

\section{INTRODUÇÃO}

Importante instituto com regulamentação prevista no Novo Código de Processo Civil (NCPC), o Recurso Extraordinário (RE) tem como finalidade maior manter a autoridade soberana e a unidade de interpretação da Constituição Federal (CF). Tal finalidade se mostra sobremodo relevante, porquanto vivemos em um sistema federativo que permite uma grande descentralização do poder judiciário e, por conseguinte, do próprio entendimento jurisprudencial.

Como se sabe, o RE é um recurso excepcional, ou seja, é admissível somente em hipóteses restritas, uma vez que o Supremo Tribunal Federal (STF) não pode ser encarado como uma terceira instância, mas uma instância extraordinária. Antigamente, o RE também abrangia as atuais hipóteses de cabimento do Recurso Especial (REsp), no entanto, com o aumento substancial dos recursos, a CF de 1988 delegou competências diversas entre o STF e Superior Tribunal de Justiça (STJ), de modo que coube a este a análise da adequada aplicação da legislação federal e àquele a guarda dos princípios e das regras contemplados pela Carta Magna.

Interposto perante o presidente ou vice-presidente do tribunal de origem, suas hipóteses de cabimento estão dispostas no art. 102, inciso III, ${ }^{1}$ do texto constitu-

1 "Art. 102. Compete ao Supremo Tribunal Federal, precipuamente, a guarda da Constituição, cabendo-lhe: [...] III - julgar, mediante recurso extraordinário, as causas decididas em única ou última 
cional, que prevê a interposição do recurso quando presentes as seguintes circunstâncias nos acórdãos recorridos: (i) contrariedade de dispositivo constitucional; (ii) declaração de inconstitucionalidade de tratado ou lei federal; (iii) julgamento considerando válida lei ou ato de governo local contestado em face da CF. Além dessas hipóteses, para sua interposição é imprescindível a observância de algumas regras, como: a necessidade de esgotamento das instâncias ordinárias, a impossibilidade de revisão de provas e matéria de fato, bem como a demonstração da repercussão geral da matéria envolvida, conforme disposição do art. $1.035,{ }^{2}$ traduzida na necessidade de o recurso tratar de uma questão que transcenda os interesses dos litigantes de ordem jurídica, econômica, social ou política.

Por fim, é importante destacar que o novo diploma legal introduziu a figura do amicus curiae ao controle difuso de constitucionalidade, isto é, o terceiro interessado pode ser admitido na causa para que traga elementos técnicos e de interesse coletivo que auxiliem efetivamente a cognição dos julgadores. Anteriormente, isso só era admissível em causas de controle de constitucionalidade abstrato.

Abordadas as ordinárias características dos RE, passaremos à análise de alguns dos institutos a eles inerentes.

\section{JUÍZO DE ADMISSIBILIDADE}

O juízo de admissibilidade consiste na verificação concreta das condições e dos pressupostos recursais. Com o advento do NCPC, alterou-se substancialmente a competência para a realização do juízo de admissibilidade, sujeitando-se a regras diferentes de um recurso para outro.

A maior celeuma se deu em face do art. 1.030 do NCPC, em sua redação original, uma vez que eliminava a previsão do código processual anterior de que tanto tribunais de segunda instância quanto cortes superiores realizassem o juízo de admissibilidade dos REsp e RE. Assim, competiria apenas aos integrantes do STJ

instância, quando a decisão recorrida: a) contrariar dispositivo desta Constituição; b) declarar a inconstitucionalidade de tratado ou lei federal; c) julgar válida lei ou ato de governo local contestado em face desta Constituição; d) julgar válida lei local contestada em face de lei federal."

2 “Art. 1.035. O Supremo Tribunal Federal, em decisão irrecorrivel, não conhecerá do recurso extraordinário quando a questão constitucional nele versada não tiver repercussão geral, nos termos deste artigo. $\S 1^{\circ}$ Para efeito de repercussão geral, será considerada a existência ou não de questões relevantes do ponto de vista econômico, político, social ou jurídico que ultrapassem os interesses subjetivos do processo." 
e do STF verificar se os recursos atendiam aos requisitos necessários para serem julgados. Entretanto, após forte pressão dos ministros, os quais sustentavam que ambos os tribunais sofreriam uma avalanche de recursos a serem analisados, o Senado aprovou, antes mesmo da entrada em vigor do NCPC, a Lei n. 13.256, a qual alterou a redação do art. 1.030 mantendo o filtro da admissibilidade de recursos ao presidente ou vice-presidente dos tribunais de justiça e do TRF.

Diante desse cenário, à luz do NCPC, o presidente ou o vice-presidente do tribunal a quo, ao final dos 15 dias concedidos ao recorrido para contrarrazoar, deverá obstar a admissibilidade do recurso extraordinário (i) quando à questão jurídica constitucional versada no recurso já não tenha sido reconhecida a repercussão geral; (ii) quando o acórdão recorrido estiver em conformidade com entendimento já adotado pelo STF em regime de repercussão geral; (iii) quando o REsp e o RE tiverem sido interpostos em face de acórdão em conformidade com decisão anterior, desses tribunais, proferida em regime de recurso repetitivo.

Percebe-se, pelo exame dessas hipóteses em que ao presidente ou ao vice-presidente caberá negar seguimento ao REsp e ao RE, um claro propósito do legislador no sentido da manutenção da estabilidade da jurisprudência, dando a lei imenso prestígio à palavra do STJ e do STF. Essa tomada de posição do legislador reflete a consciência da comunidade jurídica brasileira no sentido de que o juiz cria direito e de que o direito deve ser estável e uniforme.

O legislador também determina que o presidente ou o vice-presidente encaminhe o processo ao órgão julgador do tribunal de que faz parte para juízo de retratação quando o acórdão recorrido não estiver em consonância com o que foi decidido pelo STF ou pelo STJ, conforme o caso, nos regimes de repercussão geral ou recursos repetitivos (art. 1.030, inciso II). ${ }^{3}$

Outra providência que deverá ser tomada pelo presidente ou vice-presidente é sobrestar o processamento de recurso que versar sobre tese que já esteja afetada em regime de recurso repetitivo, REsp ou RE, para que lhes seja dado o destino apropriado depois que o paradigma for decidido (retratação ou considerar-se

3 "Art. 1.030. Recebida a petição do recurso pela secretaria do tribunal, o recorrido será intimado para apresentar contrarrazões no prazo de 15 (quinze) dias, findo o qual os autos serão conclusos ao presidente ou ao vice-presidente do tribunal recorrido, que deverá: [...] II - encaminhar o processo ao órgão julgador para realização do juizo de retratação, se o acórdão recorrido divergir do entendimento do Supremo Tribunal Federal ou do Superior Tribunal de Justiça exarado, conforme o caso, nos regimes de repercussão geral ou de recursos repetitivos; [...]." 
prejudicado o recurso) (art. 1.030, inciso III). ${ }^{4}$ É nesse momento processual, qual seja, ao final dos 15 dias concedidos ao recorrido para contrarrazoar, que poderá ocorrer no juízo a quo a seleção do recurso (REsp ou RE) para que seja o paradigma para o julgamento de muitos outros recursos no regime dos repetitivos (art. 1.030 , IV, e $\left.1.036, \int 6^{\circ}\right) \cdot{ }^{5-6}$

Por sua vez, o art. 1.030, inciso $\mathrm{V}$, atribui ao presidente ou vice-presidente $\mathrm{o}$ dever de admitir o RE ou REsp e remetê-lo ao STF ou STJ, respectivamente, desde que: (i) não seja daqueles que devam ficar sobrestados, já que estariam envolvidos em regime de recursos repetitivos; (ii) seja o recurso justamente aquele selecionado como representativo da controvérsia; (iii) já tenha sido um dos recursos cujo processamento ficou sobrestado, tendo sido posteriormente decidido o recurso paradigma, e não tenha o órgão a quo realizado o juízo de retratação (adequação àquilo que foi concedido no RE ou REsp paradigma).

Por fim, acolhendo críticas à possibilidade de que alguns dos recursos cujo processamento tenha sido sobrestado, em regime de repetitivo ou não, sejam intempestivos e que, caso ninguém percebesse, ele poderia ser decidido em conformidade com a tese adotada no RE cuja repercussão geral foi reconhecida, o NCPC permite que o interessado, ou seja, o beneficiado pela decisão atacada pelo RE pleiteie que o recurso (intempestivo e sobrestado) seja retirado da lista daqueles que estão com sua tramitação parada, para que seja inadmitido. Nesse caso, haverá coisa julgada e a decisão do segundo grau há de prevalecer, salvo se for rescindida $\left(\operatorname{art} .1 .036, \int 6^{\circ}\right)$.

\section{PREQUESTIONAMENTO}

Durante a vigência do Código de Processo Civil de 1973 (CPC/73), os tribunais superiores divergiam a respeito das formas de prequestionamento da matéria a ser alegada em sede de REsp e RE.

4 "III - sobrestar o recurso que versar sobre controvérsia de caráter repetitivo ainda não decidida pelo Supremo Tribunal Federal ou pelo Superior Tribunal de Justiça, conforme se trate de matéria constitucional ou infraconstitucional; [...]."

5 "IV - selecionar o recurso como representativo de controvérsia constitucional ou infraconstitucional, nos termos do $\S 6^{\circ}$ do art. 1.036; [...]."

6 "Art. 1.036. Sempre que houver multiplicidade de recursos extraordinários ou especiais com fundamento em idêntica questão de direito, haverá afetação para julgamento de acordo com as disposições desta Subseção, observado o disposto no Regimento Interno do Supremo Tribunal Federal e no do Superior Tribunal de Justiça. [...] $\S 6^{\circ}$ Somente podem ser selecionados recursos admissiveis que contenham abrangente argumentação e discussão a respeito da questão a ser decidida." 
Por força da Súmula n. 211/STJ, ${ }^{7}$ o STJ entendia que o prequestionamento exigia a efetiva decisão da questão federal pelo acórdão recorrido, não sendo suficiente para essa finalidade a mera oposição de embargos de declaração com fins prequestionadores caso esse recurso fosse rejeitado, porque nesse caso a omissão persistiria. Já o STF, em razão da Súmula n. 356/STF, ${ }^{8}$ entendia que, havendo a oposição de embargos, mesmo com sua rejeição, a matéria constitucional deveria ser considerada prequestionada, admitindo, portanto, o prequestionamento ficto.

Tal divergência foi resolvida pelo art. $1.025^{\circ}$ do NCPC ao prever que se consideram incluídos no acórdão os elementos que o embargante suscitou, para fins de prequestionamento, ainda que os embargos de declaração sejam inadmitidos ou rejeitados, caso o tribunal superior considere existentes erro, omissão, contradição ou obscuridade. O referido dispositivo deixa clara a admissão do prequestionamento ficto, de forma que, mesmo a matéria não sendo expressamente decidida em grau inferior, tendo o recorrente interposto embargos de declaração com essa finalidade, já será o suficiente para a admissão do REsp ou RE pelo preenchimento do pressuposto de admissibilidade do prequestionamento.

Vale ressaltar que tanto o STJ quanto o STF entendem que só haverá prequestionamento ficto, nos termos do art. 1.025 do NCPC, quando a não apreciação pelo tribunal local da matéria federal/constitucional ali suscitada em embargos de declaração for reconhecida, pela corte superior, como verdadeira e indevida recusa daquele tribunal a sanar existente erro, omissão, contradição ou obscuridade constante do acórdão embargado. ${ }^{10}$ Exigem, diante desse entendimento, que no RE/ REsp seja indicada violação ao art. $1.022^{11}$ do NCPC para que se possibilite ao órgão

7 "Inadmissivel recurso especial quanto à questão que, a despeito da oposição de embargos declaratórios, não foi apreciada pelo tribunal a quo."

8 "O ponto omisso da decisão, sobre o qual não foram opostos embargos declaratórios, não pode ser objeto de recurso extraordinário, por faltar o requisito do prequestionamento."

9 "Art. 1.025. Consideram-se incluídos no acórdão os elementos que o embargante suscitou, para fins de pré-questionamento, ainda que os embargos de declaração sejam inadmitidos ou rejeitados, caso o tribunal superior considere existentes erro, omissão, contradição ou obscuridade."

10 Nesse sentido: STJ, 3a Turma, Aglnt no REsp n. 1.680.099/SP, Rel. Min. Ricardo Villas Bôas Cueva, julgado em: 12 dez. 2017, DJe: 02 fev. 2018; STF, 1a Turma, ARE n. 960.736 AgR/SP, Rel. Min. Alexandre de Moraes, julgado em: 19 jun. 2017, DJe: 29 jun. 2017.

11 "Art. 1.022. Cabem embargos de declaração contra qualquer decisão judicial para: I - esclarecer obscuridade ou eliminar contradição; II - suprir omissão de ponto ou questão sobre o qual devia se pronunciar o juiz de oficio ou a requerimento; III - corrigir erro material. Parágrafo único. Considera-se omissa a decisão que: I - deixe de se manifestar sobre tese firmada em julgamento de 
julgador verificar a existência do vício inquinado ao acórdão, que, uma vez constatado, poderá dar ensejo à supressão de grau facultada pelo dispositivo de lei. ${ }^{12}$

\section{REENVIO - DIFICULDADES DECORRENTES DA INCONSTITUCIONALIDADE REFLEXA}

$\mathrm{Na}$ vigência do CPC/73, era comum o STJ inadmitir REsp sob o fundamento de que a matéria nele tratada seria de índole constitucional e, portanto, passível de RE. Vice-versa, também o STF inadmitia RE em razão do caráter infraconstitucional da questão recursal debatida.

Ocorre que nem sempre é possível distinguir com precisão o caráter constitucional ou infraconstitucional da questão debatida, havendo, indiscutivelmente, zona cinzenta em que não se encontra resposta isenta de crítica ou contestação. Em importante inovação, o NCPC resolveu o problema com dois artigos, $1.032^{13}$ e 1.033. ${ }^{14}$ Diferentemente do que ocorre na hipótese do art. 1.031, eles não tratam de dois recursos, RE e REsp, interpostos concomitantemente. Há, aqui, apenas um recurso, e a discussão sobre quem é competente para julgá-lo depende do enfoque que seja dado à matéria nele versada.

$\mathrm{O}$ art. 1.032 cuida da hipótese de o relator, no STJ, entender que o RE versa sobre questão constitucional. Neste caso, deverá conceder prazo de 15 dias para que o recorrente demonstre a existência de repercussão geral - exigência específica do RE, por força do art. 102, $\int 3^{\circ}$, inciso III, da CF - e se manifeste sobre a questão constitucional. Depois, o relator enviará o recurso ao STF, que poderá

casos repetitivos ou em incidente de assunção de competência aplicável ao caso sob julgamento; II - incorra em qualquer das condutas descritas no art. 489, § $1^{0}$."

12 Nesse sentido: STJ, $3^{a}$ Turma, Resp n. 1.639.314/MG, Rel. Min. Nancy Andrighi, julgado em: 4 abr. 2017, DJe: 10 abr. 2017; STJ, $2^{\text {a }}$ Turma, EDcl no REsp n. 1.673.323/RS, Rel. Min. Herman Benjamin, julgado em: 28 nov. 2017, DJe: 19 dez. 2017.

13 "Art. 1.032. Se o relator, no Superior Tribunal de Justiça, entender que o recurso especial versa sobre questão constitucional, deverá conceder prazo de 15 (quinze) dias para que o recorrente demonstre a existência de repercussão geral e se manifeste sobre a questão constitucional. Parágrafo único. Cumprida a diligência de que trata o caput, o relator remeterá o recurso ao Supremo Tribunal Federal, que, em juízo de admissibilidade, poderá devolvê-lo ao Superior Tribunal de Justiça."

14 "Art. 1.033. Se o Supremo Tribunal Federal considerar como reflexa a ofensa à Constituição afirmada no recurso extraordinário, por pressupor a revisão da interpretação de lei federal ou de tratado, remetê-lo-á ao Superior Tribunal de Justiça para julgamento como recurso especial." 
devolvê-lo ao STJ caso entenda o contrário, isto é, que em verdade a questão não é constitucional (art. 1.032, parágrafo único). Nesse caso, é importante notar, a despeito do silêncio do dispositivo, que aquele óbice deve ser superado pelo STJ e, nesse sentido, o recurso deve ser conhecido e julgado.

A hipótese oposta é regulada pelo art. 1.033, o qual dispõe que se o relator do RE entender que a hipótese é, em verdade, de questão infraconstitucional "por pressupor a revisão da interpretação de lei federal ou de tratado", deve enviar o recurso para julgamento ao STJ como REsp. Aqui, diferentemente do que se dá no art. 1.032, não há previsão para o STJ recusar sua competência, que, em última análise, deriva da própria CF (art. 105, inciso III) e encontra no STF seu guardião-mor. Tanto quanto na hipótese anterior, portanto, é irrecusável que o STJ julgue o recuso. Diferença sensível, contudo, é que aqui o STJ ainda não proferiu juízo de admissibilidade recursal e, em rigor, pode fazê-lo a ponto de não conhecer do recurso desde que não infirme a decisão já proferida pelo STF.

Ambas as regras representam importante novidade trazida pelo NCPC para combater as dificuldades decorrentes da "inconstitucionalidade reflexa", que, em termos práticos, acaba gerando um verdadeiro vácuo de competência. Ademais, cabe acentuar que ambos os dispositivos são reflexo inquestionável do modelo de "processo cooperativo" desejado pelo NCPC.

\section{REPERCUSSÃO GERAL}

A Emenda Constitucional (EC) n. 45/2004 introduziu no ordenamento jurídico brasileiro o instituto da repercussão geral das questões constitucionais. Com isso, o art. 102, $\int 3^{\circ}$, inciso III, da CF passou a dispor: "No recurso extraordinário o recorrente deverá demonstrar a repercussão geral das questões constitucionais discutidas no caso, nos termos da lei, a fim de que o Tribunal examine a admissão do recurso, somente podendo recusá-lo pela manifestação de dois terços de seus membros".

Tal instituto nada mais é que um filtro para que o STF possa efetivamente dirigir o foco de sua atividade para questões que têm maior relevância para a sociedade, ou seja, aquilo que tem repercussão geral. Esse mecanismo de filtragem tem três objetivos principais: (i) diminuir o número de processos no STF; (ii) uniformizar a interpretação constitucional sem exigir que a corte decida múltiplos casos idênticos sobre a mesma questão constitucional; e (iii) firmar o papel desse tribunal como corte constitucional e não instância recursal, delimitando sua competência 
no julgamento de RE a questões constitucionais com relevância social, política, econômica ou jurídica, que transcendam os interesses subjetivos da causa.

Tratando-se de condição de admissibilidade do RE, é ônus do recorrente cumprir o requisito (art. $1.035,{ }^{15} \int 2^{\circ}$ ). A consequência da desatenção desse ônus, qual seja, o não conhecimento do recurso, está capitulada expressamente no caput do art. 1.035: "O Supremo Tribunal Federal, em decisão irrecorrível, não conhecerá do recurso extraordinário quando a questão constitucional nele versada não tiver repercussão geral, nos termos deste artigo".

A tarefa de aferir a repercussão geral das questões constitucionais não é fácil. Dispõe o $\int 1^{\circ}$ do art. 1.035: "Para efeito de repercussão geral, será considerada a existência ou não de questões relevantes do ponto de vista econômico, político, social ou jurídico que ultrapassem os interesses subjetivos do processo". Verifica-se, portanto, que os dois elementos caracterizadores da qualificação da repercussão geral, segundo se extrai do referido dispositivo, são a relevância (que pode ser econômica, política, social ou jurídica) e a transcendência (que ultrapassa os interesses subjetivos do processo).

Existem, ainda, algumas hipóteses envolvendo questões constitucionais em que há presunção de existência de repercussão geral. A versão original do NCPC trazia três casos em que haveria repercussão geral presumida. No entanto, na Lei n. 13.256/2016 suprimiu-se uma dessas situações, restando apenas duas, quais sejam: (i) quando o RE tiver sido interposto contra acórdão que contrarie súmula ou jurisprudência dominante do próprio STF (mesmo que se trate de decisões proferidas em ações individuais, em que a inconstitucionalidade tenha sido analisada incidenter tantum); e (ii) se o RE impugnar acórdão que tenha reconhecido a inconstitucionalidade de tratado ou lei federal, proferida de acordo com o art. 97 da CF, ou seja, pelo voto da maioria absoluta dos membros do pleno ou do órgão especial de tribunal de segundo grau (TSJ ou TRF).

No inciso suprimido constava a hipótese de o RE impugnar acórdão proferido em julgamento de casos repetitivos. Dessa forma, só não resta presumida a repercussão geral em acórdão que julga REsp repetitivo. Imprescindível observar-se,

15 “Art. 1.035. O Supremo Tribunal Federal, em decisão irrecorrivel, não conhecerá do recurso extraordinário quando a questão constitucional nele versada não tiver repercussão geral, nos termos deste artigo. $\S 1^{\circ}$ Para efeito de repercussão geral, será considerada a existência ou não de questões relevantes do ponto de vista econômico, político, social ou juridico que ultrapassem os interesses subjetivos do processo. $\S 2^{\circ} \mathrm{O}$ recorrente deverá demonstrar a existência de repercussão geral para apreciação exclusiva pelo Supremo Tribunal Federal." 
ainda, que a apreciação do requisito da repercussão geral se faz exclusivamente no STF. A competência para tanto é do pleno, por decisão de pelo menos oito dos onze ministros, conforme dispõe o art. 102, $\int 3^{\circ}$, inciso III, da CF, sendo irrecorrível tal decisão.

No que se refere aos efeitos do reconhecimento da repercussão geral, na vigência do CPC/73, a interpretação do art. 543-B, $\int 1^{\circ}$, desse diploma levava à conclusão de que somente deveriam ser sobrestados os RE que versassem sobre questão cuja repercussão geral fosse reconhecida pelo STF. Nada impedia, assim, o prosseguimento dos demais recursos e processos que tratassem do tema. ${ }^{16}$ Já no NCPC, altera-se substancialmente tal sistemática, estabelecendo o $\int 5^{\circ}$ do art. $1.035^{17}$ que, "reconhecida a repercussão geral, o relator no Supremo Tribunal Federal determinará a suspensão do processamento de todos os processos pendentes, individuais ou coletivos, que versem sobre a questão e tramitem no território nacional".

Poderá ocorrer, também, de RE ser interposto intempestivamente e, ainda assim, restar sobrestado por força da decisão de que trata o $\int 5^{\circ}$ do art. 1.035 . Nesse caso, a parte recorrida é prejudicada pelo impedimento do trânsito em julgado da decisão objeto do recurso. Por conta disso, prevê o $\int 6^{\circ}$ do art. $1.035^{18}$ a possibilidade de o interessado requerer ao presidente ou ao vice-presidente do tribunal de origem a imediata inadmissão do recurso intempestivamente interposto, desconsiderando-se, assim, a decisão de sobrestamento. Nessa situação, terá o recorrente o prazo de 5 dias para manifestar-se sobre esse requerimento. Se a existência de repercussão geral for negada, os recursos sobrestados nos termos do $\int 5^{\circ}$ do art. 1.035, que só podem ser os que versem sobre matéria idêntica, terão seu seguimento negado pelo presidente ou vice-presidente do tribunal de origem $\left(\right.$ art. $\left.1.035, \int 8^{\circ}\right) .{ }^{19}$

16 REsp n. 1143677/RS, Rel. Min. Luiz Fux, Corte Especial, julgado em: 2 dez. 2009, DJe: 4 fev. 2010.

17 "Art. 1.035. O Supremo Tribunal Federal, em decisão irrecorrivel, não conhecerá do recurso extraordinário quando a questão constitucional nele versada não tiver repercussão geral, nos termos deste artigo."

18 " $\$ 6^{\circ} \mathrm{O}$ interessado pode requerer, ao presidente ou ao vice-presidente do tribunal de origem, que exclua da decisão de sobrestamento e inadmita o recurso extraordinário que tenha sido interposto intempestivamente, tendo o recorrente o prazo de 5 (cinco) dias para manifestar-se sobre esse requerimento."

19 "Art. 1.035. O Supremo Tribunal Federal, em decisão irrecorrivel, não conhecerá do recurso extraordinário quando a questão constitucional nele versada não tiver repercussão geral, nos termos deste artigo. [...] $\S 8^{\circ}$ Negada a repercussão geral, o presidente ou o vice-presidente do tribunal 
Por fim, na hipótese oposta, quando a repercussão geral for reconhecida, caberá ao STF julgar o RE no prazo máximo de 1 ano, tendo preferência sobre os demais processos, com exceção dos pedidos de habeas corpus e dos casos que envolvam réu preso (art. 1.035, $\sqrt{ } 9^{\circ}$ ). ${ }^{20} \mathrm{~A}$ consequência do descumprimento desse prazo era a cessão automática da suspensão dos processos repetitivos sobrestados, conforme previsão contida no $\ 10^{\circ}$ do art. 1.035 do NCPC. Ocorre, entretanto, que tal dispositivo foi revogado pela Lei n. 13.256/2016, de forma que resta sem qualquer consequência processual o descumprimento de tal prazo.

\section{RECURSOS REPETITIVOS}

O NCPC, estendendo-se do art. 1.036 ao art. 1.041, traz algumas modificações no processamento e no julgamento dos RE e REsp repetitivos no STF e no STJ, respectivamente.

O rito dos recursos repetitivos dispõe que, quando houver multiplicidade de RE ou REsp com fundamento em idêntica questão de direito, a análise do recurso pode ocorrer por amostragem, mediante a seleção de recursos que representem de maneira adequada a controvérsia. O art. 1.037 do NCPC determina que, após selecionado(s) o(s) recurso(s) como repetitivo, o ministro relator do STJ ou do ST proferirá decisão de afetação em que deverá (i) identificar com precisão a questão a ser submetida a julgamento; e (ii) determinar a suspensão de processamento de todos os processos pendentes, individuais ou coletivos, que versem sobre a questão e tramitem no território nacional.

O sobrestamento de todos os processos, em qualquer grau de jurisdição, parece ser a alteração que trará mais efetividade à ideia de um poder judiciário mais célere, isonômico e estável no que tange às teses repetitivas. Trata-se de norma de cumprimento obrigatório pelos ministros do STJ e do STF que tem por objetivo evitar decisões conflitantes sobre uma questão já afetada à análise dos tribunais superiores e, ao mesmo tempo, agilizar o trâmite dos processos com matéria idêntica. Seguramente, se o sobrestamento se desse automaticamente aos temas de recurso

de origem negará seguimento aos recursos extraordinários sobrestados na origem que versem sobre matéria idêntica."

20 "§ $9^{\circ} \mathrm{O}$ recurso que tiver a repercussão geral reconhecida deverá ser julgado no prazo de 1 (um) ano e terá preferência sobre os demais feitos, ressalvados os que envolvam réu preso e os pedidos de habeas corpus." 
repetitivo ou repercussão geral já existentes teria um impacto ainda maior. No entanto, nesses poucos anos de aplicação do NCPC, o que se pode sentir é que os tribunais - de justiça e regionais federais - somente sobrestarão seus processos mediante decisão do STF ou do STJ nesse sentido.

O NCPC, objetivando fomentar o prévio debate sobre a tese a ser julgada no recurso afetado como repetitivo, regula algumas situações, como as audiências públicas (art. 1.038, ${ }^{21}$ inciso II), nas quais será permitida a oitiva de depoimentos de pessoas com experiência e conhecimento na matéria com a finalidade de instruir o procedimento, e a intervenção do amicus curiae (art. 1.038, inciso I), ou seja, pessoas, órgãos ou entidades com interesse na controvérsia.

$\mathrm{O}$ art. $1.039^{22}$ ocupa-se dos recursos que foram sobrestados e estão no âmbito dos próprios tribunais superiores. Para eles, decidido o repetitivo, os recursos que estavam sobrestados, por tratarem da mesma controvérsia, serão considerados prejudicados ou decididos com a aplicação da tese fixada. Por sua vez, o art. $1.040^{23}$ é

21 “Art. 1.038. O relator poderá: I - solicitar ou admitir manifestação de pessoas, órgãos ou entidades com interesse na controvérsia, considerando a relevância da matéria e consoante dispuser o regimento interno; II - fixar data para, em audiência pública, ouvir depoimentos de pessoas com experiência e conhecimento na matéria, com a finalidade de instruir o procedimento; III requisitar informações aos tribunais inferiores a respeito da controvérsia e, cumprida a diligência, intimará o Ministério Público para manifestar-se. $\S 1^{\circ}$ No caso do inciso III, os prazos respectivos são de 15 (quinze) dias, e os atos serão praticados, sempre que possivel, por meio eletrônico. $\S 2^{\circ}$ Transcorrido o prazo para o Ministério Público e remetida cópia do relatório aos demais ministros, haverá inclusão em pauta, devendo ocorrer o julgamento com preferência sobre os demais feitos, ressalvados os que envolvam réu preso e os pedidos de habeas corpus. $\S 3^{\circ} \mathrm{O}$ conteúdo do acórdão abrangerá a análise dos fundamentos relevantes da tese jurídica discutida."

22 "Art. 1.039. Decididos os recursos afetados, os órgãos colegiados declararão prejudicados os demais recursos versando sobre idêntica controvérsia ou os decidirão aplicando a tese firmada. Parágrafo único. Negada a existência de repercussão geral no recurso extraordinário afetado, serão considerados automaticamente inadmitidos os recursos extraordinários cujo processamento tenha sido sobrestado."

23 "Art. 1.040. Publicado o acórdão paradigma: I - o presidente ou o vice-presidente do tribunal de origem negará seguimento aos recursos especiais ou extraordinários sobrestados na origem, se o acórdão recorrido coincidir com a orientação do tribunal superior; II - o órgão que proferiu o acórdão recorrido, na origem, reexaminará o processo de competência originária, a remessa necessária ou o recurso anteriormente julgado, se o acórdão recorrido contrariar a orientação do tribunal superior; III - os processos suspensos em primeiro e segundo graus de jurisdição retomarão o curso para julgamento e aplicação da tese firmada pelo tribunal superior; IV - se os recursos versarem sobre questão relativa a prestação de serviço público objeto de concessão, permissão ou autorização, o resultado do julgamento será comunicado ao órgão, ao ente ou à 
vocacionado para regrar os efeitos que o julgamento do repetitivo pelo STF ou pelo STJ surta sobre os processos até então suspensos nos tribunais de justiça, nos tribunais regionais federais e também na primeira instância.

Na perspectiva do NCPC, o que se espera é que a decisão do recurso afetado seja necessariamente observada pelos demais órgãos jurisdicionais. Tal afirmação fica ainda mais clara com o quanto previsto no art. $927,{ }^{24}$ o qual estabelece que os acórdãos proferidos em julgamento de RE e REsp repetitivos deverão ser observados por juízes e tribunais de segunda instância, deixando apenas de ser seguidos, conforme o art. 489, inciso VI, mediante a demonstração pelo magistrado de existência de distinção no caso em julgamento ou superação do entendimento firmado.

\section{A VINCULABILIDADE DOS PRECEDENTES}

Apesar de o sistema jurídico adotado pelo Brasil ser o civil law, é possível observar o aumento da presença de algumas características do common law, cuja finalidade é proporcionar maior segurança jurídica aos jurisdicionados, como ocorre com os precedentes judiciais.

O NCPC privilegiou a uniformização e a estabilização da jurisprudência dos tribunais, garantindo a efetividade do processo, bem como a proteção às garantias constitucionais. Essa tendência decorre da necessidade de oferecer soluções idênticas para casos concretos congêneres, de modo que as decisões encontrem respaldo no mesmo fundamento jurídico, evitando a insegurança jurídica diante do mesmo caso concreto e o excesso de recursos aos tribunais sobre o mesmo tema e atendendo, desse modo, às expectativas de um Estado Democrático de Direito.

Desde o CPC/73, observava-se certa assimilação da stare decisis - decisões prolatadas por determinado órgão do judiciário que criam um precedente e vinculam as que serão emitidas futuramente, isto é, têm força obrigatória -, na medida em

agência reguladora competente para fiscalização da efetiva aplicação, por parte dos entes sujeitos a regulação, da tese adotada."

24 "Art. 927. Os juízes e os tribunais observarão: I - as decisões do Supremo Tribunal Federal em controle concentrado de constitucionalidade; II - os enunciados de súmula vinculante; III - os acórdãos em incidente de assunção de competência ou de resolução de demandas repetitivas e em julgamento de recursos extraordinário e especial repetitivos; IV - os enunciados das súmulas do Supremo Tribunal Federal em matéria constitucional e do Superior Tribunal de Justiça em matéria infraconstitucional; $\vee$ - a orientação do plenário ou do órgão especial aos quais estiverem vinculados." 
que os juízos a quo são recomendados a aplicar a jurisprudência dos tribunais superiores, além da aplicação de súmulas vinculantes, reconhecimento de inconstitucionalidade de determinada lei e demandas repetitivas.

A EC n. 45/2004 foi o principal marco quanto à incorporação de precedentes ao ordenamento jurídico brasileiro, pois, concomitantemente à reforma do poder judiciário, inseriu as súmulas vinculantes e a obrigatoriedade da repercussão geral nos RE, nos termos do art. 102, inciso III, \ $3^{\circ}$, da CF. Com o NCPC, essa vinculação tornou-se ainda mais clara, uma vez que o art. $926^{25}$ dispõe que os tribunais uniformizarão suas jurisprudências com o objetivo de mantê-la estável, íntegra e coerente, prevendo ainda a edição de súmulas que reportem à jurisprudência majoritária, limitando-se às circunstâncias dos casos concretos que levaram à sua criação.

Cabe ressaltar que o NCPC determina a aplicação dos precedentes, não se tratando de uma faculdade ao magistrado sua aplicação, mas uma imperatividade. Todavia, a vinculação dos precedentes não importa em supressão de cognição do juiz em relação às provas, do livre convencimento fundamentado e da análise das circunstâncias factuais, uma vez que o juiz pode não seguir os precedentes caso a situação concreta seja diversa da que ensejou a criação do precedente, situação em que ele demonstrará os motivos pelos quais o precedente não se aplica ao litígio. Ainda nesse sentido, a utilização deste mecanismo oferece plena segurança jurídica, pois, em sua decisão, o magistrado deverá fundamentar os motivos pelos quais aplicará o precedente, não bastando indicá-lo.

No tocante à modulação dos efeitos dos precedentes, via de regra, o entendimento exarado pelas cortes superiores é aplicado às demandas pendentes de julgamento, independentemente da jurisprudência consolidada à data do ajuizamento da ação, mas, por outro lado, as ações decididas definitivamente de acordo com o entendimento anterior não podem ser alteradas em virtude da modulação de efeitos.

$\mathrm{Na}$ doutrina encontram-se duas vertentes sobre o tema, sendo que a primeira defende a utilização de precedentes judiciais vinculantes, visto que oferecem

25 “Art. 926. Os tribunais devem uniformizar sua jurisprudência e mantê-la estável, íntegra e coerente. $\S 1^{\circ} \mathrm{Na}$ forma estabelecida e segundo os pressupostos fixados no regimento interno, os tribunais editarão enunciados de súmula correspondentes a sua jurisprudência dominante. $\S 2^{\circ}$ Ao editar enunciados de súmula, os tribunais devem ater-se às circunstâncias fáticas dos precedentes que motivaram sua criação." 
vantagens aos litigantes: segurança jurídica, estabilidade do ordenamento jurídico, previsibilidade mediante análise dos casos anteriores, coerência, imparcialidade do juiz, desestímulo ao ajuizamento de demandas cujo direito pleiteado seja no sentido contrário do entendimento consolidado pelos tribunais etc. Em contrapartida, há doutrinadores que entendem que esse sistema traz prejuízos na medida em que não permite o desenvolvimento do direito e engessa decisões aos casos concretos, além de afetar a independência dos juízes.

Diante de uma ponderação entre as vantagens e as desvantagens da vinculação dos precedentes, as vantagens parecem ser maiores e essa é a opinião majoritária de doutrinadores e magistrados, razão pela qual a tendência da vinculação de precedentes é o aperfeiçoamento de sua aplicação.

\section{CONSIDERAÇÕES FINAIS}

Diante das alterações trazidas pelo NCPC, ao disciplinar os REsp e RE, percebe-se que o legislador buscou simplificar a regulamentação da matéria, dando-lhe uma linguagem mais didática e prática aos operadores do direito.

Igualmente, regulamentou de maneira mais pormenorizada o processamento desses recursos, evitando-se discussões colaterais e procrastinatórias sobre o tema. 